\title{
AVALIAÇÃO NUTRICIONAL DA PROTEÍNA DE AMÊNDOAS DE BOCAIÚVA, Acrocomia aculeata (Jacq.) Lodd., EM RATOS WISTAR EM CRESCIMENTO
}

\author{
PRISCILA AIKO HIANE * \\ MARIA LÍGIA RODRIGUES MACEDO ** \\ GABRIELA MORAES SILVA *** \\ JOSÉ ANTÔNIO BRAGA NETO *
}

\begin{abstract}
Efetuou-se avaliação nutricional da proteína da amêndoa de bocaiúva, Acrocomia aculeata (Jacq.) Lodd., mediante determinação do Balanço Nitrogenado (BN), Digestibilidade Verdadeira (DV), Valor Biológico (VB), Razão de Eficiência Protéica (PER) e composição em aminoácidos. Realizou-se ensaio com 24 ratos machos Wistar, alimentados com as dietas controle (caseína), teste (farinha de amêndoa de bocaiúva) e aprotéica, todas preparadas de acordo com o protocolo do American Institute of Nutrition. As dietas controle e teste foram formuladas de maneira a serem isoprotéicas. Verificou-se durante 29 dias a quantidade de ração ingerida e o ganho de peso corporal dos animais, determinando-se o nitrogênio urinário e metabólico. A farinha desengordurada de amêndoa de bocaiúva apresentou alto teor de proteína $(38,0 \%)$ e de fibra $(45,3 \%)$. Ratos tratados com a dieta-teste apresentaram menor balanço nitrogenado $(2,0)$, menor ganho de peso $(42,8 \mathrm{~g})$ e menor capacidade de promover a digestibilidade de proteínas $(83,5 \%)$ que os tratados com caseína (respectivamente, 3,3; $55,5 \mathrm{~g}$ e $95,5 \%$ ). Pelo perfil de aminoácidos da amostra, a treonina constitui o aminoácido essencial mais limitante (escore químico de $41,8 \%$ ) em relação ao padrão da $\mathrm{FAO} / \mathrm{WHO}$, sendo encontrados teores elevados de valina, isoleucina, fenilalanina+tirosina, metionina+cisteína e lisina. A proteína da amêndoa da bocaiúva, embora com alto valor biológico $(81,1 \%)$, apresentou qualidade nutricional mais baixa que a caseína padrão quanto aos outros índices avaliados. Conclui-se que é possível utilizar amêndoas de bocaiúva para suplementar dietas, especialmente quando adotadas formas de preparo que melhorem sua digestibilidade.
\end{abstract}

PALAVRAS-CHAVE: QUALIDADE PROTÉICA; ENSAIO BIOLÓGICO; BOCAIÚVA; Acrocomia aculeata.

- Professores, Departamento de Tecnologia de Alimentos e Saúde Pública, Universidade Federal de Mato Grosso do Sul (UFMS), Campo Grande (MS), Brasil (e-mail: prihiane@nin.ufms.br).

* Professora, Departamento de Ciências Naturais, UFMS, Três Lagoas (MS), Brasil.

"* Bolsista de Iniciação Científica, Programa PIBIC, Curso de Farmácia-Bioquímica, UFMS, Campo Grande (MS), Brasil. 


\section{INTRODUÇÃO}

A bocaiúva pertence à família Palmae, espécie Acrocomia aculeata (Jacq.) Lodd., sendo abundante e nativa no Estado de Mato Grosso do Sul (MS). Ocorre em mata mesofítica, sendo conhecida popularmente por bacaiuveira, bacaúva, coco-balão, coco-baboso, cocode-catarro, coco-de-espinha, coco-xodó, embocaia, macaiba, macaiá, macajá, macajuba, macaúba, macaúva, macujá, marcová e mucajá (ALMEIDA, 1998). Apresenta uma semente cuja amêndoa comestível pode ser consumida in natura ou na forma de doces, como a paçoca e a cocada (ALMEIDA, 1998; SILVA et al. 1994; ALMEIDA et al. 1998).

As nozes (amêndoas) de bocaiúva apresentam teor de proteínas elevado (HIANE et al. 1992), porém não são encontrados dados sobre o perfil aminoacídico e as propriedades nutricionais das sementes desse fruto.

Sementes de espécies de plantas nativas, como as do cerrado, vêm sendo estudadas a fim de avaliar o potencial de aproveitamento de frutos comestíveis regionais. No Brasil, TOGASHI e SGARBIERI (1995) estudaram sementes de baru (Dypterix alata Vog) e MATUDA e MARIA NETTO (2005) sementes de jatobá-do-cerrado (Hymenaea stigonocarpa Mart.). As duas espécies do cerrado brasileiro podem constituir fontes de proteínas e carboidratos (baru) e de fibras (jatobá), mas ambas apresentam deficiência em aminoácidos sulfurados na fração protéica.

As proteínas dos alimentos podem ser classificadas conforme sua digestibilidade, proporção e biodisponibilidade de aminoácidos (NIELSEN, 1991; PELLET e YOUNG, 1980; HENLEY e KUSTER, 1994). A qualidade da proteína resulta do seu valor nutritivo. Em geral, as proteínas de origem animal apresentam maior valor nutritivo que as de origem vegetal (CARIAS, CIOCCIA e HEVIA, 1995).

A dieta da população brasileira pode indicar, muitas vezes, a origem de problemas de saúde pela qualidade nutritiva precária. Ocorrem nas diferentes regiões padrões alimentares mais ou menos incompletos e dissonantes (MADRUGA et al. 2004; BRANDÃO e BRANDÃO, 1996). No entanto, o Brasil dispõe de recursos naturais e de alternativas agrícolas que podem atender e/ou suplementar satisfatoriamente dietas nutricionalmente deficientes. São exemplos a soja, a algaroba, a 
castanha-do-Brasil e outras matérias-primas regionais (como o piqui, bocaiúva, bacuri e baru) que oferecem alto teor protéico (HIANE et al. 1992; VIEIRA e BION, 1998; SOUZA e MENEZES, 2004; TOGASHI e SGARBIERI, 1995).

No presente trabalho avaliou-se a qualidade protéica da amêndoa de bocaiúva, Acrocomia aculeata (Jacq.) Lodd., mediante determinação do Balanço Nitrogenado (BN), Digestibilidade Verdadeira (DV), Valor Biológico (VB), Razão de Eficiência Protéica (PER) e composição em aminoácidos da fração protéica da amêndoa do fruto.

\section{MATERIAL E MÉTODOS}

\subsection{MATÉRIA-PRIMA}

Foram coletados no campus da Universidade Federal de Mato Grosso do Sul (UFMS), Campo Grande-MS, frutos maduros de bocaiúva, Acrocomia aculeata (Jacq.) Lodd., entre novembro e dezembro de 2003. As amêndoas dos frutos foram retiradas, trituradas em triturador Turratec e passadas em tamis 60 mesh, constituindo a farinha-base integral. A farinha da amêndoa de bocaiúva foi desengordurada com éter de petróleo p.a. (PE - $30-60^{\circ} \mathrm{C}$ ) e utilizada para estudo das proteínas quanto à sua composição em aminoácidos e digestibilidade in vivo.

\subsection{COMPOSIÇÃO CENTESIMAL}

Realizou-se a determinação da composição centesimal da farinha desengordurada de amêndoa de bocaiúva, visando obtenção de dados a serem utilizados na formulação da ração para o ensaio biológico protéico. Submeteu-se a amostra desengordurada à determinação do teor de lipídios remanescentes pelo método de extração direta com solvente orgânico em aparelho de Soxhlet (IAL, 1985).

A determinação de umidade ocorreu por dessecação em estufa a $105^{\circ} \mathrm{C}$ (método gravimétrico), conforme procedimento do IAL (1985). Determinou-se a proteína pelo conteúdo de nitrogênio total (\%), segundo o método microKjeldahl (AOAC, 1992), usando o fator 6,25 para conversão do nitrogênio em proteínas. As cinzas (resíduo mineral fixo) foram determinadas pelo método gravimétrico (incineração em mufla a 
$550^{\circ} \mathrm{C}$ ) conforme o IAL (1985) e a fibra pelo método da fibra detergente neutro (VAN SOEST e WINE, 1967), obtendo-se os glicídios totais por diferença.

\subsection{COMPOSIÇÃO EM AMINOÁCIDOS}

As proteínas de amêndoas de bocaiúva foram extraídas com $150 \mathrm{~mL}$ de cloreto de sódio a $4 \%$, durante $1 \mathrm{~h}$, de acordo com MACEDO e DAMICO (2000). As análises de aminoácidos foram executadas conforme HENRIKSON e MEREDITH (1984), utilizando-se analisador de aminoácido Pico-Tag (Waters System). Realizou-se a hidrólise protéica com HCl $6 \mathrm{M} / \mathrm{fenol} 1 \%$, a $106^{\circ} \mathrm{C}$ por $24 \mathrm{~h}$, cujo hidrolisado reagiu com $20 \mu \mathrm{L}$ de solução de derivatização recentemente preparada (metanol: trietilamina: água: fenilisotiocianato, 7:1:1:1, v/v) por $1 \mathrm{~h} \mathrm{em}$ temperatura ambiente. Após derivatização na pré-coluna, os aminoácidos foram identificados em coluna HPLC de fase reversa, comparando-se os tempos de retenção dos aminoácidos da amostra com os dos padrões (Pierce). Resíduos de cisteína foram quantificados como ácido cistéico. Com os valores da composição em aminoácidos estimou-se o escore de aminoácidos essenciais (EAE), segundo HENLEY e KUSTER (1994), no qual EAE (\%) = aminoácido mais limitante na proteína teste/mesmo aminoácido no padrão de referência FAO/WHO (1991) X 100.

\subsection{AVALIAÇÃO NUTRICIONAL}

Para avaliação nutricional das proteínas foram elaborados três tipos de rações (dietas) que caracterizaram os três diferentes tratamentos aplicados: ração aprotéica (grupo aprotéico), ração-padrão/caseína (grupo controle) e ração-teste, contendo farinha desengordurada da amêndoa de bocaiúva (grupo teste).

Para elaboração das rações seguiu-se o procedimento do American Institute of Nutrition (REEVES, NIELSEN e FAHEY, 1993) para ratos, efetuando-se modificações de acordo com a composição centesimal da farinha desengordurada da amêndoa de bocaiúva. As rações foram preparadas de maneira a conter aproximadamente $10 \%$ de proteína, $8 \%$ de lipídios, $11 \%$ de fibra (celulose), $10 \%$ de sacarose, $1 \%$ de mistura vitamínica, $4 \%$ de mistura salina (mineral) e $0,1 \%$ de benzoato de sódio. Ajustou-se o teor de lipídios das rações formuladas para $8 \%$ 
com óleo de soja.

Também ajustou-se o teor de fibra considerando a composição centesimal da farinha de amêndoa de bocaiúva. Na dieta aprotéica, livre de proteína, esse ingrediente foi substituído pelo amido de milho em quantidade suficiente para completar a composição (100\%). Usouse a dieta livre de proteína para estimar a excreção de nitrogênio endógeno e metabólico dos ratos.

As quantidades relativas de ingredientes que compuseram as dietas estão apresentadas na Tabela 1.

\section{TABELA 1 - COMPOSIÇÃO DAS DIETAS UTILIZADAS NO ENSAIO BIOLÓGICO PROTÉICO DA AMÊNDOA DE BOCAIÚVA,}

Acrocomia aculeata (Jacq.) Lodd

\begin{tabular}{lccc}
\hline $\begin{array}{l}\text { Componentes } \\
\text { (em gramas) }\end{array}$ & Aprotéica & Caseína & Bocaiúva $^{1}$ \\
\hline Caseína (82,6\% de proteína) & - & 12,11 & - \\
Farinha de bocaiúva $^{*}$ & - & - & 26,35 \\
Fibra** (celulose microfina) $^{*}$ & 11,16 & 11,16 & 11,16 \\
Sacarose* $^{*}$ & 10,00 & 10,00 & 10,00 \\
Mistura salina** (mineral) $_{\text {Mistura vitamínica* }}$ & 4,00 & 4,00 & 4,00 \\
Óleo vegetal (óleo de soja) $_{\text {Amido de milho*** }}$ & 1,00 & 1,00 & 1,00 \\
Benzoato de sódio & 8,00 & 8,00 & $7,68^{\star *}$ \\
\hline \% de proteína & 65,74 & 53,63 & 39,71 \\
\hline
\end{tabular}

1 Farinha desengordurada da amêndoa de bocaiúva.

* Conforme o American Institute of Nutrition (REEVES, NIELSEN e FAHEY, 1993).

** Ajustado(a) conforme a composição centesimal da farinha desengordurada da amêndoa de bocaiúva.

${ }^{* * *}$ Alterado em quantidade suficiente para completar a composição $(100 \%)$. 
Determinou-se a composição centesimal das dietas experimentais para verificar se os ingredientes encontravam-se nas quantidades previamente formuladas (teores de proteínas na Tabela 1).

No experimento conduzido no Biotério Central da UFMS, durante 29 dias, foram utilizados 24 ratos machos da linhagem Wistar, recémdesmamados, com 22 dias de idade e peso médio inicial de 38,96 g. O protocolo experimental foi aprovado pela Comissão de Ética no Uso de Animais da UFMS.

No ensaio biológico, os animais foram individualmente colocados em gaiolas metabólicas numeradas e divididos em três grupos de oito animais por meio de sorteio a fim de que essa divisão representasse distribuição aleatória. Cada grupo de animais passou a ser alimentado (29 dias) com as diferentes dietas preparadas e água ad libitum. Os animais foram mantidos em ambiente limpo, com temperatura controlada $\left(25^{\circ} \mathrm{C}\right)$, luminosidade adequada, alternando-se períodos de claro e escuro de 12 horas.

Realizou-se controle do peso corporal dos animais e do consumo da ração ao longo do experimento mediante pesagens dos animais, da ração oferecida e de sobras em dias alternados (DE LUCA, ALEXANDRE e MARQUES, 1996) para determinação da Razão de Eficiência Protéica (PER) (PELLET e YOUNG, 1980; NAS, 1963). O registro dos dados foi realizado até que os ratos atingissem 51 dias de idade.

A partir da segunda semana, além de se registrar o ganho de peso e o consumo de dieta de cada animal, as fezes e a urina foram coletadas para o cálculo do Balanço Nitrogenado (BN) e dos índices de utilização biológica da proteína. Usando-se as dietas (indicadas na Tabela 1) foram obtidos os parâmetros Digestibilidade Verdadeira (DV) e Valor Biológico (VB) (PELLET e YOUNG, 1980; NAS, 1963; SGARBIERI, 1987).

\subsection{ANÁLISES ESTATÍSTICAS}

Os resultados foram submetidos à Análise de Variância (ANOVA), com nível de significância de $5 \%$, a fim de verificar diferença entre os 
dois grupos experimentais (controle e teste) (PIMENTEL-GOMES, 2000).

\section{RESULTADOS E DISCUSSÃO}

A composição centesimal aproximada da farinha desengordurada da amêndoa de bocaiúva, $A$. aculeata (Jacq.) Lodd (Tabela 2), evidenciou altos teores de proteína $(37,95 \%)$ e de fibra $(45,32 \%)$.

\section{TABELA 2 - COMPOSIÇÃO CENTESIMAL DA FARINHA DESENGORDURADA DA AMÊNDOA DE BOCAIÚVA, Acrocomia aculeata (Jacq.) Lodd., EXPRESSA EM BASE ÚMIDA E SECA}

\begin{tabular}{lcc}
\hline Componentes & $\begin{array}{c}\text { Base Úmida } \\
(\mathrm{g} / 100 \mathrm{~g})\end{array}$ & $\begin{array}{c}\text { Base Seca } \\
(\mathrm{g} / 100 \mathrm{~g})\end{array}$ \\
\hline Proteína $(\mathrm{N} \times 6,25)$ & $37,95 \pm 0,47$ & $41,34 \pm 0,52$ \\
Lipídios totais & $1,23 \pm 0,03$ & $1,34 \pm 0,03$ \\
Cinzas & $4,78 \pm 0,02$ & $5,20 \pm 0,03$ \\
Fibra total & $45,32 \pm 1,97$ & $49,37 \pm 2,05$ \\
Glicídios totais (diferença) & 2,52 & 2,74 \\
Umidade & $8,20 \pm 0,06$ & - \\
\hline
\end{tabular}

Médias de 3 determinações \pm desvio-padrão.

O padrão de proporcionalidade de aminoácidos e a digestibilidade são determinantes da qualidade protéica (FAO/WHO, 1991). A presença de um ou mais aminoácidos essenciais em concentrações adequadas melhora o valor protéico da dieta (CARIAS, CIOCCIA e HEVIA, 1995; NAS, 1963). Comparou-se a composição em aminoácidos da amostra estudada (Tabela 3) ao padrão de referência para aminoácidos essenciais, recomendado pela FAO/WHO (1991) para crianças de 2 a 5 anos de idade. Os resultados mostraram que a proteína da amêndoa de bocaiúva é deficiente em treonina, histidina e leucina. A treonina (escore químico de 41,8\%) revelou-se o aminoácido mais limitante na amostra para crianças de 2 a 5 anos de idade. A amêndoa mostrou- 
se, potencialmente, boa fonte de valina, metionina+cisteína, isoleucina, fenilalanina+tirosina e lisina para crianças de 2 a 5 anos de idade, cujos teores foram mais altos do que os valores recomendados para ingestão pela FAO.

\section{TABELA 3 - COMPOSIÇÃO EM AMINOÁCIDOS DA AMÊNDOA DE BOCAIÚVA, Acrocomia aculeata (Jacq.) Lodd}

\begin{tabular}{lcc}
\hline Aminoácidos (mg/g de proteína) & Bocaiúva & FAO $^{1}$ \\
\hline Ácido aspártico & 66,4 & \\
Ácido glutâmico & 156,4 & \\
Serina & 60,8 & \\
Glicina & 74,7 & 19 \\
Histidina & 12,3 & \\
Arginina & 134,6 & 34 \\
Treonina & $14,2^{*}$ & \\
Alanina & 77,8 & \\
Prolina & 72,4 & \\
Tirosina & 23,9 & 35 \\
Valina & 68,9 & 25 \\
Metionina + Cisteína & 25,2 & 28 \\
Isoleucina & 34,2 & 66 \\
Leucina & 63,5 & 63 \\
Fenilalanina + tirosina & 65,4 & 58 \\
Lisina & 73,1 & 11 \\
Triptofano & $\mathrm{ND}$ & \\
EAE (\%) & $41,8(\mathrm{Thr})$ & \\
Padro & & \\
\hline
\end{tabular}

${ }_{1}^{1}$ Padrão teórico da FAO/WHO (1991) (aminoácidos indispensáveis para crianças de 2 a 5 anos de idade); * Aminoácido mais limitante; ND = Não-determinado; Médias de duas repetições.

$\mathrm{Na}$ Tabela 4 encontram-se os dados relacionados ao ganho de peso, consumo de proteína e de nitrogênio e os valores médios da Razão de Eficiência Protéica (PER) dos animais. Já a Figura 1 apresenta as 
curvas de crescimento dos ratos submetidos às dietas experimentais.

TABELA 4 - GANHO DE PESO, CONSUMO DE PROTEÍNA, NITROGÊNIO INGERIDO E RAZÃO DE EFICIÊNCIA PROTÉICA (PER) EM RATOS SUBMETIDOS À DIETA CONTENDO CASEÍNA (CONTROLE) E AMÊNDOA DE BOCAIÚVA, Acrocomia aculeata (Jacq.) Lodd (TESTE) DURANTE 29 DIAS

\begin{tabular}{ccccc}
\hline Dieta & $\begin{array}{c}\text { Ganho } \\
\text { de peso } \\
(\mathrm{g})\end{array}$ & $\begin{array}{c}\text { Consumo de } \\
\text { proteína } \\
(\mathrm{g})\end{array}$ & $\begin{array}{c}\text { Nitrogênio } \\
\text { ingerido } \\
(\mathrm{g})\end{array}$ & PER \\
\hline Caseína & $55,46^{\star} \pm 7,61$ & $27,33 \pm 2,93$ & $4,28 \pm 0,08$ & $2,03^{\mathrm{NS}} \pm 0,14$ \\
Bocaiúva & $42,79^{\star} \pm 3,53$ & $18,37 \pm 1,75$ & $2,94 \pm 0,36$ & $2,34^{\mathrm{NS}} \pm 0,25$ \\
\hline
\end{tabular}

Valores médios \pm desvio-padrão.

NS = Não-significativo.

* Significativo ao nível de $5 \%$ de probabilidade $(p<0,05)$.

O ganho de peso do grupo que recebeu a ração-caseína mostrou-se maior que o grupo que recebeu a ração-teste, com diferença significativa ao nível de $5 \%(p<0,05)$.

Os primeiros cinco dias de experimento, em média, são considerados de adaptação à dieta (NAS, 1963; SGARBIERI, 1987). Tal fato pode explicar a semelhança do comportamento da curva de crescimento dos três tratamentos no início do ensaio. Após esse período, o grupo controle caracterizou-se pelo ganho de peso mais elevado que os demais grupos. Deve-se destacar que o grupo aprotéico apresentou perda de peso. Ao relacionar o ganho de peso dos animais à quantidade de proteína consumida durante os 29 dias de experimento foram obtidos valores de PER bem próximos.

TOGASHI e SGARBIERI (1995) estudaram a proteína de sementes de baru (Dypterix alata Vog) e observaram grande diferença de PER entre a proteína da dieta com caseína (controle) e a com baru. Atribuiram o fato à deficiência acentuada de aminoácidos sulfurados (metionina e cisteína) nas sementes estudadas. 


\section{FIGURA 1 - VARIAÇÃO DE PESO DOS RATOS ALIMENTADOS DURANTE 29 DIAS COM DIETA APROTÉICA, DIETA COM AMÊNDOA DE BOCAIÚVA, Acrocomia aculeata (Jacq.) Lodd E DIETA CONTENDO CASEÍNA}

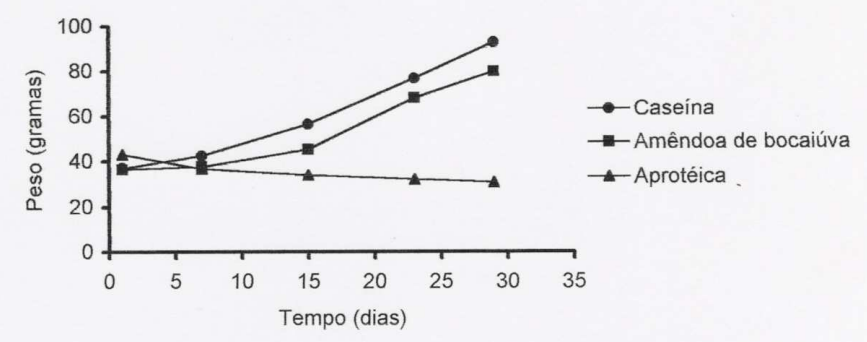

O balanço nitrogenado encontrado para cada grupo foi positivo, o que é típico de animais em crescimento (o anabolismo é mais intenso do que o catabolismo). Assim, o nitrogênio ingerido foi superior à soma do nitrogênio excretada pelas vias fecal e urinária evidenciando retenção de nitrogênio (significativamente maior para o grupo controle). Pelo balanço de nitrogênio (Tabela 5) são obtidos dados sobre o valor nutricional das proteínas, calculando-se os índices de Digestibilidade (D) e Valor Biológico (VB) (NAS, 1963; SGARBIERI, 1987).

\section{TABELA 5 - NITROGÊNIO FECAL E URINÁRIO, BALANÇO NITROGENADO (BN), DIGESTIBILIDADE VERDADEIRA (DV) E VALOR BIOLÓGICO (VB) DA PROTEÍNA DE AMÊNDOA DA BOCAIÚVA, Acrocomia aculeata (Jacq.) Lodd EM COMPARAÇÃO COM A CASEÍNA PADRÃO}

\begin{tabular}{lccccc}
\hline Dieta & \multicolumn{2}{c}{ Nitrogênio $(\mathrm{g})$} & BN & DV & VB \\
& Fecal & Urinário & & $(\%)$ & $(\%)$ \\
\hline Caseína & $0,27 \pm 0,04$ & $0,81 \pm 0,04$ & $3,34^{\star} \pm 0,07$ & $95,48^{*} \pm 0,98$ & $81,69^{\mathrm{NS}} \pm 1,27$ \\
Bocaiúva & $0,56 \pm 0,05$ & $0,52 \pm 0,07$ & $1,99^{\star} \pm 0,36$ & $83,51^{*} \pm 3,19$ & $81,10^{\mathrm{NS}} \pm 3,25$ \\
\hline
\end{tabular}

* Significativo ao nível de $5 \%$ de probabilidade $(p<0,05)$.

NS= Não-significativo.

Valores são médias \pm desvio-padrão. 
A digestibilidade, determinante da qualidade protéica da dieta, mede a porcentagem das proteínas que são hidrolisadas pelas enzimas digestivas e absorvidas na forma de aminoácidos, ou de qualquer outro composto nitrogenado pelo organismo. Proteínas, cujas ligações peptídicas não são hidrolisadas pelo processo digestivo, são excretadas nas fezes ou sofrem transformações no intestino grosso (MACEDO e DAMICO, 2000; SGARBIERI, 1987; MAGA, LORENZ e ONAUEMI, 1973).

A maioria das proteínas de origem animal apresenta boa digestibilidade, o que significa eficaz absorção de aminoácidos. As de origem vegetal geralmente são inferiores em razão de terem estruturas mais organizadas e resistentes ao ataque enzimático (CARIAS, CIOCCIA e HEVIA, 1995; MAGA, LORENZ e ONAUEMI, 1973). A digestibilidade encontrada para a caseína neste ensaio está de acordo com SGARBIERI (1987) que observou 96\% de digestibilidade para essa proteína. No presente estudo, o valor da digestibilidade da proteína da dieta contendo farinha da amêndoa de bocaiúva $(83,51 \%)$ diferiu significativamente $(p<0,05)$ do valor da dieta com caseína $(95,48 \%)$.

Estudos da FAO/WHO (1991) e da FAO/WHO/UNU (1985) identificaram vários fatores que contribuem para a menor digestibilidade das proteínas de alimentos vegetais em relação às proteínas animais. A presença de fatores dietéticos (compostos fenólicos, componentes da fibra alimentar, pigmentos, inibidores de enzimas e outros) modificam a digestão e as reações químicas que alteram a liberação de aminoácidos e de proteínas por processos enzimáticos. Em relação às amêndoas de bocaiúva, dados deveriam ser obtidos no sentido de mostrar se suas frações protéicas contêm ou não inibidores de proteases e lectinas que poderiam estar interferindo na digestibilidade dessas sementes.

A presença de fibra, notavelmente polissacarídios estruturais de paredes celulares, e suas interações com proteínas podem reduzir a acessibilidade da proteína à proteólise, causando redução de digestibilidade (GALLAND-IRMOULI et al. 1999; MELITO e TOVAR, 1995). Sabe-se que a fibra pode interferir na absorção de alguns minerais, dificultando o crescimento de animais de experimento (BEDNAR et al. 2001). A influência de fibras na digestibilidade protéica da amêndoa de bocaiúva deveria ser investigada. 
O valor biológico da proteína teste (farinha da amêndoa de bocaiúva) mostrou-se estatisticamente igual ao da caseína ( $p>0,05)$. Provavelmente, os aminoácidos limitantes da proteína da amêndoa de bocaiúva não interferiram no aproveitamento global da proteína quanto à proporção de nitrogênio (proteína) retida pelo organismo do total absorvido.

A avaliação nutricional da amêndoa de bocaiúva evidenciou valores significativamente mais baixos para ganho de peso (GP), consumo de proteína $(C P)$, balanço nitrogenado (BN) e digestibilidade (D) em relação à ração controle (caseína) para ratos. Os resultados de digestibilidade e o valor biológico foram similares aos obtidos por TOGASHI e SGARBIERI (1995) que observaram D menor nas dietas contendo proteína de origem vegetal.

O uso da farinha desengordurada da amêndoa de bocaiúva em formulações destinadas à alimentação humana (como alternativa para obter proteínas nutricionalmente de boa qualidade) exige a inclusão de outros alimentos que supram suas deficiências. Sugere-se também a alteração na sua forma de preparo para consumo (como cozimento ou tostagem) para melhorar a digestibilidade da farinha.

\section{CONCLUSÃO}

A farinha desengordurada da amêndoa de bocaiúva, apresentando alto teor de proteína e fibra, mostrou deficiência protéica quanto aos aminoácidos essenciais treonina, histidina e leucina.

A proteína da amêndoa de bocaiúva evidenciou menor capacidade de promover crescimento e digestibilidade que a caseína. No entanto, o valor biológico protéico da amêndoa teste foi semelhante ao da caseína padrão (controle).

Pode-se utilizar amêndoa de bocaiúva como fonte alternativa de proteína, especialmente no preparo da merenda escolar e para atender populações sem acesso às proteínas de origem animal. Entretanto, deve-se pesquisar diferentes formas de preparo da matéria-prima que possam influenciar na biodisponibilidade dos seus aminoácidos e também suplementos para suprir suas deficiências. 
Sugere-se a investigação da influência de inibidores de proteases, taninos, fitatos e fibras na digestibilidade da proteína dessa amêndoa.

\begin{abstract}
NUTRITIONAL EVALUATION OF PROTEIN FROM KERNELS OF BOCAIÚVA, Acrocomia aculeata (Jacq.) Lodd., IN GROWING WISTAR RATS

The purpose of this investigation was to evaluate in nutritional terms the protein from kernels of bocaiúva, Acrocomia aculeata (Jacq.) Lodd., by determining the Nitrogen Balance (NB), Protein Efficiency Ratio (PER), True Digestibility (TD), and Biological Value (BV), and the amino acid composition. The assay was conducted with 24 Wistar male rats fed on the diets containing casein (control), defatted bocaiúva kernel flour (test) and aproteic according to the protocol of the American Institute of Nutrition. Test flour and casein formulations were prepared to be isoprotein diets. For 29 days, the amounts of ingested experimental diets and body weight gains were recorded and analyses were made to determine urinary and metabolic nitrogen. The defatted kernel flour of bocaiúva presented high content of protein $(38.0 \%)$ and fiber $(45.3 \%)$. Rats treated with the test diet as compared with those fed on diet containing casein showed significantly $(p<0.05)$ lower indexes for nitrogen balance (2.0), body weight gain (42.8g), and protein digestibility (83.5\%). For casein group, the values were respectively of $3.3 ; 55.5 \mathrm{~g}$ and $95.5 \%$. The amino acid profile revealed that although the studied sample showed threonine as the most limiting amino acid (chemical score $41.8 \%$ ) relative to the FAO-WHO requirement patterns, had high contents of valine, isoleucine, phenylalanine + tyrosine, methionine + cysteine and lysine. Despite its high biological value, the kernel protein of bocaiúva $(81.1 \%)$ had lower nutritional quality than the casein standard in relation to the other evaluated indexes. The results showed that kernel can be used as supplementary feeding, especially if improved with suitable forms of preparation that can promote its digestibility.
\end{abstract}

KEY-WORDS: PROTEIN QUALITY; KERNEL; BIOLOGICAL ASSAY; BOCAIÚVA; Acrocomia aculeata.

\title{
REFERÊNCIAS
}

1 ALMEIDA, S.P. Cerrado: aproveitamento alimentar. Planaltina: EMBRAPA-CPAC, 1998. $188 \mathrm{p}$.

2 ALMEIDA, S.P.; PROENÇA, C.E.B.; SANO, S.M.; RIBEIRO, J.F. Cerrado: espécies vegetais úteis. Planaltina: Embrapa - CPAC; 1998. 464 p.

3 AOAC. Association of Official Analytical Chemists. Official methods of analysis of AOAC International. $12^{\text {th }}$ ed. Washington, 1992. $1115 \mathrm{p}$. 
BEDNAR, G.E.; PLATIL, A.R.; MURRAY, S.M.; GRIESHOP, C.M.; MERCHEN, N.R.; FAHEY, G.C. Starch and fiber fractions in selected food and feed ingredients affect their small intestinal digestibility and fermentability and their large bowel fermentability in vitro in a canine model. Journal of Nutrition, v.131, n.2, p. 276-286, 2001.

5 BRANDÃO, T.C.C.; BRANDÃO, R.F. Alimentação alternativa. Brasília: INAN/Ministério da Saúde, 1996. 95 p.

CARIAS, D.; CIOCCIA, A.M.; HEVIA, P. Grado de concordancia entre la digestibilidad de proteínas animales y vegetales medidas in vivo e in vitro y su efecto sobre el cómputo químico. Arch. Latinoam. Nutrición., v. 45, n. 2, p. 111-116, 1995.

DE LUCA, R.R.; ALEXANDRE, S.R.; MARQUES, T. Manual para técnicos em bioterismo. São Paulo: Winner Graph, 1996. 259 p.

FAO/WHO. Food and Agriculture Organization/World Health Organization. Necessidades de energia y de proteínas. Ginebra: OMS, 1985. 220 p. (Informe de una réunion consultiva conjunta $\mathrm{FAO/OMS/UNU}$ de expertos).

FAO/WHO. Food and Agriculture Organization/World Health Organization. Evaluation of protein quality. Rome: FAO, Food Nutrition, 1991. (Report of the Joint FAO/WHO expert consultation on protein quality evaluation).

10 GALLAND-IRMOULI, A.V.; FLEURENCE, J.; LAMGHARY, R.; LUCON, M.; ROUXEL, C.; BARBAROUX, O.; BRONOWICKI, J.P.; VILLAUME, C.; GUÉANT, J.L. Nutritional value of proteins from edible seaweed Palmaria palmata (Dulse). Journal of Nutrition Biochemistry, v.10, p. 353-359, 1999.

11 HENLEY, E.C.; KUSTER, J.M. Protein quality evaluation by protein digestibility - corrected amino acid scoring. Food Technology, v. 48, n. 4 , p. $74-77,1994$.

12 HENRIKSON, R.L.; MEREDITH, S.C. Amino acid analysis by reverse phase high performance liquid chromatography: precolumn derivatization with phenylisothiocyanate. Analytical Biochemistry, v.136, p. 65-71, 1984.

HIANE, P.A.; RAMOS, M.I.L.; RAMOS FILHO, M.M.R.; PEREIRA, J.G. 
Composição centesimal e perfil de ácidos graxos de alguns frutos nativos do Estado de Mato Grosso do Sul. Boletim do CEPPA, v.10, n.1, p. 35-42, 1992.

14 IAL. Instituto Adolfo Lutz. Normas analíticas do Instituto Adolfo Lutz. 3. ed. São Paulo, 1985. v.1. 533 p.

15 MACEDO, M.L.R.; DAMICO, D.C.S. Effects of protein fractions from Zea mays $\mathrm{L}$. on development and survival of mexican bean weevil Zabrotes subfasciatus (Boh.). Insect Sci. Applic., v.20, p. 135139, 2000.

MADRUGA, M.S.; SANTOS, H.B.; BION, F.M.; ANTUNES, N.L.M. Avaliação nutricional de uma dieta suplementada com multimistura: estudo em ratos. Ciência e Tecnologia de Alimentos, v.24, n.1, p. 129-133, 2004.

17 MAGA, J.A.; LORENZ, K.; ONAUEMI, O. Digestive acceptability of proteins as measured by the initial rate of in vitro proteolisis. Journal Food Science, v.38, p. 173-174, 1973.

MATUDA, T.G.; MARIA NETTO, F. Caracterização química parcial da semente de jatobá-do-cerrado (Hymenaea stigonocarpa Mart.). Ciência e Tecnologia de Alimentos, v. 25, n. 2, p. 353-357, 2005.

MELITO, C.; TOVAR, J. Cell walls limit in vitro protein digestibility in processed legume seed. Food Chemistry, v.53, p. 305-307, 1995.

NAS. National Academy of Science. National Research Council. Evaluation of protein quality. Washington, $1963.74 \mathrm{p}$.

21 NIELSEN, S.S. Digestibility of legume protein. Food Technology, v.45, n.6, p. 112-114, 1991.

PELLET, P.L.; YOUNG, V.R. Nutritional evaluation of protein food. Tokyo: The United University, 1980. 136 p.

PIMENTEL-GOMES, F. Curso de estatística experimental. 14. ed. Piracicaba: Nobel. 2000. 477 p.

REEVES, P.G.; NIELSEN, F.H.; FAHEY, G.C. AIN-3 purified diets for laboratory rodents: final report of the American Institute of Nutrition ad hoc writing Committee on the reformulation of the AIN-76A 
rodent diet. Journal of Nutrition, v.123, n.10, p.1939-1952, 1993.

25 SGARBIERI, V.C. Métodos de avaliação da qualidade nutricional dos alimentos. In: SGARBIERI, V.C. Alimentação e nutrição: fator de saúde e desenvolvimento. São Paulo: Almed, 1987. p.250261.

26 SILVA, J.A.; SILVA, D.B.; JUNQUEIRA, N.T.V.; ANDRADE, L.R.M. Frutas nativas dos cerrados. Brasília: EMBRAPA-CPAC. EMBRAPA-SPI, 1994. $166 \mathrm{p}$.

27 SOUZA, M.L.; MENEZES, H.C. Processamento de amêndoa e torta de castanha-do-Brasil e farinha de mandioca: parâmetro de qualidade. Ciência e Tecnologia de Alimentos, v.24, n.1, p. 120128, 2004.

28 TOGASHI, M.; SGARBIERI, V.C. Avaliação nutricional da proteína e do óleo do baru (Dypterix alata Vog). Ciência e Tecnologia de Alimentos, v.15, n. 1, p. 66-69, 1995.

29 VAN SOEST, P.J.; WINE, R.H. Use of detergents in the analysis of fibrous foods. IV. Determination of plant wall constituents. Journal of AOAC, v.50, n.1, p. 50-55, 1967.

30 VIEIRA, R.L.; BION, F.M. Valor biológico de dieta a base de soja (Glycine hispide) e algaroba (Prosopis juliflora). Boletim do CEPPA, v.16, n.1, p. 58-98, 1998. 